\title{
A Study on Smart Phone Assisted Learning System
}

\author{
Dan Xie ${ }^{1, a}$, Xiuzhi Zhao ${ }^{2, b}$ and Xiaohuan Yang ${ }^{1, c}$ \\ ${ }^{1}$ School of Information Engineering, Hubei University of Chinese Medicine, Wuhan 430065, China; \\ atonghua123@sina.com, b2768565509@qq.com, '582901377 @qq.com
}

Keywords: Classroom assisted; mobile learning; smart phone; WeChat Platform development

\begin{abstract}
With the rapid development of mobile phone technology, the usage of smart phones has become more and more popular, in which mobile application has been successfully adopted in the field of business, government, social management, and higher education. The new technology leads the change of classroom teaching mode. This paper firstly analyzes the teaching mode of university classroom, pointing out the limitations of traditional classroom teaching. The paper then points out the new learning model of smart phone assisted classroom teaching based on mobile technology. Finally, using a programming course as an example, the university classroom assisted learning system is designed in detail based on smart phone. The actual application result shows that this system has achieved fine effects in assisted learning.
\end{abstract}

\section{Introduction}

The classroom teaching is the main teaching form of the school, especially in colleges and universities. The traditional classroom teaching form focus on imparting knowledge, which cannot think about the individual development in collective behavior according to the unified training mode, and it is not conducive to the students' individual learning and growth. On the teaching form, mainly through the classroom which is specialized channel and a single pattern, the aspects of teaching students in accordance of their aptitude and opening up channels of extracurricular need to be strengthened. If there is only the traditional classroom teaching method, it is difficult to meet the needs of students' individualized learning development and adaption to the rapid development of modern society [1, 2].

\subsection{Information Technology Promote the Transformation of Classroom Learning Mode.}

The rapid development of Internet technology and mobile communication technology has great impact on study, work and life. Mobile technology is applied to the field of education, especially the universities in which the mobile network coverage expands and there are great prospects. With the rapid popularization of users who hold intelligent mobile terminal, the mode with intelligent terminal assisted classroom learning gradually integrates into the university teaching nowadays, and the advantages of mobile learning integrating into classroom learning are gradually highlighted [3]. It is a hot spot in the field of educational technology to explore and research how the intelligent mobile terminal application to teaching, to create intelligent learning environment for students and to optimize the teaching process and improve the quality of teaching. For example, the development of the classroom data visualization based on the network intelligence may bring a new revolution of classroom form and optimize teachers' technology application [4].Today there are more and more diversified modes of learning in the world. A lot of education and training institutions have not only the physical classroom, but also more online classroom, such as WeChat, QQ platform, micro blog and other teaching methods; classroom learning is gradually developing towards the online learning. The development tendency of training institutions prompted us from the side, that the single teaching form will be difficult to sustain in the era of mobile technology [5].

\subsection{Mobile Learning Platform for College Classroom Teaching}

In the case of the use of smartphone, the university campus is one of the most suitable place to give priority to the development of mobile learning. Not only because most of the students are equipped with mobile learning equipment, but an open learning environment also contributes to the university teachers to improve the existing classroom learning ways, in order to solve the problem that the 
college students generally like looking at mobile phones, playing games on the class, even skipping from the class. And to ameliorate the university classroom "traffic charges" status and to narrow the distance between teachers and students, we need to start from the needs of students to understand students' interest and change the concept of learning and innovative learning mode, which makes the students feel the university curriculum is not only teachers teaching, but by blended learning of a variety of learning modes integrated each other. A new teaching model, based on smart phone for mobile learning, need teachers' active promotion and students' coordination, in the process of communication and interaction it makes learn more efficient with this new way of learning, so as to guide the students to learn actively.

\section{The Design of Classroom Learning Mode Based on Smart Phone}

With the increasing number of college students which bring smart mobile phone entered the classroom, the traditional classroom learning has been influenced seriously by the mobile technology. According to the survey, WeChat and QQ App is the most widely used mobile phone software by the current college students [6]. It will receive unexpected results if the classroom learning can make most use of the mobile phone terminal' teaching software to improve classroom learning. Integrating the smart phones into classroom learning activities, creating the enhanced classroom learning environment, enriching the forms of classroom learning environment, and carrying out effective teacher-student and student-student communication activities, these can improve the performance of classroom learning activities, and promote the new classroom learning paradigm's formation [7].

\subsection{The Design of System Architecture}

This paper combines the traditional classroom learning mode and mobile learning mode, which is supported by mobile technology as the breakthrough point, to reexamine classroom learning activities, based on the actual situation of classroom teaching in universities and colleges and under the guidance of the concept of mobile learning and scaffolding teaching, combined with enhanced classroom learning environment's the advantages and characteristics and constructs the support of mobile technology classroom learning model. By the use of the Internet, teachers will transfer classroom learning content and related resources to the classroom assisted system of WeChat support platform, learners through smart phones, personal computers and other devices according to themselves' learning needs to learn the resources from the classroom assisted learning system, and then promote the classroom learning.

\subsection{The Design of Learning Mode}

The learning mode in the design should give full consideration to the mobility of students' learning environment, so there are certain technical requirements on the development environment. As software which is focused on the mobile terminal's function, WeChat can provide space for the application of mobile learning. WeChat's real-time communication and good use experience make it possess higher use rate and adhesion degree for students. A variety of interactive modes make information interaction be enable to become more flexible, WeChat support platform will enable application development of mobile learning more convenient and efficient. Tencent Company support a variety of functions' permissions for WeChat public service platform, and different permissions have appropriate regulations on the function of mass texting and development of the system function [8].

Mobile learning based on WeChat platform should follow the design principle of clear position, reasonable function, scientific content, rich interaction, flexible learning and communication service, which let WeChat learning supporting functions integrate into the curriculum and teaching design [9]. Due to the push of information is restricted on the number aspect, it need teachers and developers to choose carefully in information push and take the essence of the knowledge point and information to push to the students and then to enhance students' understanding of the curriculum content. The diagram of the classroom learning model based on WeChat platform as shown in Figure 1 and the classroom learning mode can achieve the following functions on teaching: 


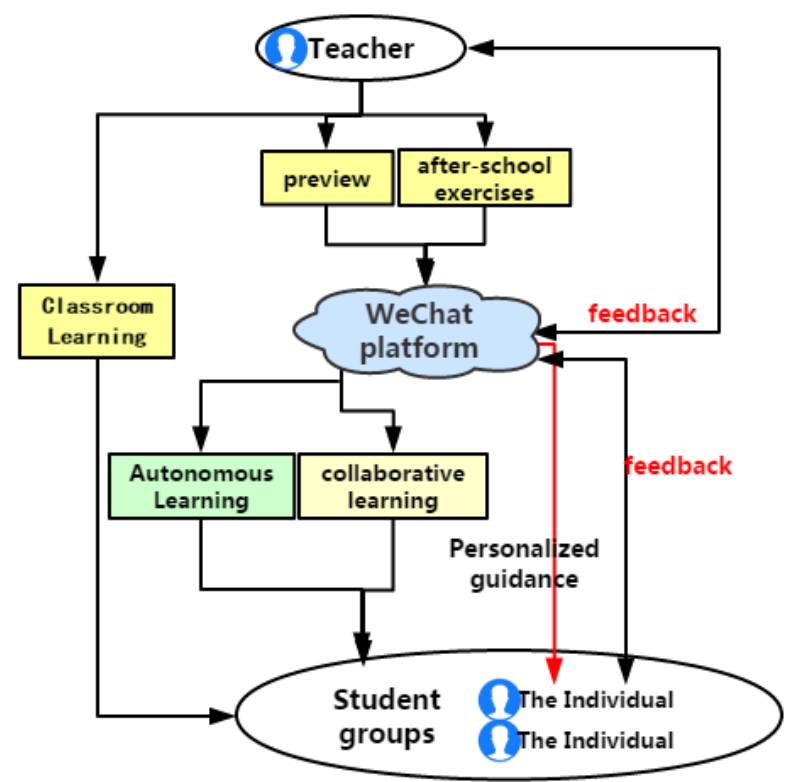

Fig. 1 Schematic diagram of classroom assisted learning model under the support of WeChat

(1)Assisted Classroom Teaching. WeChat class as the extension and supplement of classroom teaching, one of the main functions is to consolidate and strengthen the knowledge of the classroom. According to the actual classroom teaching, classroom teaching can be divided into three stages. The first is the preview stage, according to the progress of the curriculum teaching content on the upcoming released in advance, especially about the emphases and difficulties of teaching content, which is convenient for students to master the learning content and make the classroom preparation in advance and grasp the course schedule. The second is the classroom teaching stage, surrounding the current classroom knowledge points, the main form has two kinds, one kind is the traditional text and pictures, and the other is micro video. Micro video usually has a relatively short time, and it can be watch through the smart phone. The form of different types will be selected according to teaching content and supplemented with micro video when text and pictures cannot achieve the desired teaching effect. The last is the lifting stage after class, teachers will publish assignments to test the effect of teaching after the completion of the actual classroom teaching task and release standard answer after student's submitting the homework to let the students deepen the understanding of knowledge after compared with the standard answer. In addition, the latest information related to the course will be selected and published by the teacher to expand the students' knowledge and enrich the course's learning content.

(2)Promoting Autonomous Learning. Test is one of commonly methods of examining the effect of self-study. In order to carry out the evaluation on the students' learning effect, two stages which is before and after the class are respectively provided with a prediction area and operation area. The prediction area provides one or two questions, which help students understand their mastering degree; homework area is used to show the classroom work in order to test the understanding of the knowledge degree. At the beginning of the semester, the teachers set the proportion of usually results, final results, and usually results include attendance, homework completion and inform the students. Each time the students submitte homework, the form of the classroom attendance, homework completion and situation of each homework's response will be released by the teachers to let the students be clear of their usually results and their level in the whole class. For more experimental courses, the experimental results also can be increased, and so method on. Though pre-test, submitting homework, and whole class evaluation results, students can understand themselves and others better and promote their autonomous learning.

(3)Opening Collaborative Learning. An important reason to choose WeChat platform is that it can provide multi-user instant communication. Multi-user interaction is not only between teachers and students, but also between students and students. Group discussion is not only conducive to the students to think actively, but also helps develop collaborative learning among the students. Through 
the discussion, knowledge sparks is expected to be generated and early embryonic form of student research team is expected to be formed. At the same time, teachers and students under the same learning goal have mutual cooperation and mutual promotion to make teachers become students' collaborator and guide and make students become a source of inspiration for teachers to reach a win-win situation.

(4)Achieving Personalized Guidance. Classroom teaching is a group activity, and individual students with different abilities have a different learning progress. For the problems students meet in the learning process, students can ask the teacher on the platform. Teachers can see all the questions of students, and they can choose the representative problems to explaine uniformly in the next class, and teachers also can start one-to-one answer selectively. Through the personalized guidance between teachers and students, let some students who are less willing to communicate facing with the teacher have an online communication channels, which not only can stimulate students' learning enthusiasm and help to improve the effect of classroom teaching and to promote teacher-student relationship more harmonious, but also at the same time the teacher can get timely feedback, timely adjustment of the progress of the course, teaching form and improvement of the quality of teaching.

\section{The Analysis of WeChat Platform Example of the Classroom Assisted Learning System}

\subsection{The Analysis of User}

According to the learning model above, this paper develops a classroom assisted learning system based on WeChat platform. The users are college teachers and students who are using smart phone. As a complement to classroom teaching, from the point of view that the cost saving and practicability, the writer select the authentication subscription number (the type of government) of the public service platform of WeChat as a development platform, who supports Android and iPhone operating system. There are three types of users of the system, which are teachers, students and administrators. The teacher is learning resource providers and need to upload effective assisted classroom learning resources to student. At the same time, teachers who are the observer of teaching effect, besides teaching, need to design questionnaire to get the timely feedback of students. The students are learning resource recipients, also need to know timely the content of classroom learning and start autonomous learning to make up for the lack of classroom learning; at the same time, the student also can actively upload information, and have discussions with teachers and students. The administrator, who is a guarantor of system operation, is mainly responsible for system maintenance, data backup, information security, user management and other work, to ensure the normal operation of the WeChat classroom learning system [10]. According to the three different types of users, that the friendly user interface and detailed help information, simple operation process, intimate communication coaches should be the focus in the design of classroom assisted learning system to make all users of the system make good use of the system through simple training to guarantee assisted classroom teaching to achieve the desired effect.

\subsection{Functional Design}

Classroom assisted learning system function design bases on the demand analysis, and student is the main body in the three types of users, and because of the limited space, there is only the design of the students' user, and focuses on classroom learning. The function structure diagram of the custom menu of WeChat after logging is shown in figure 2. 


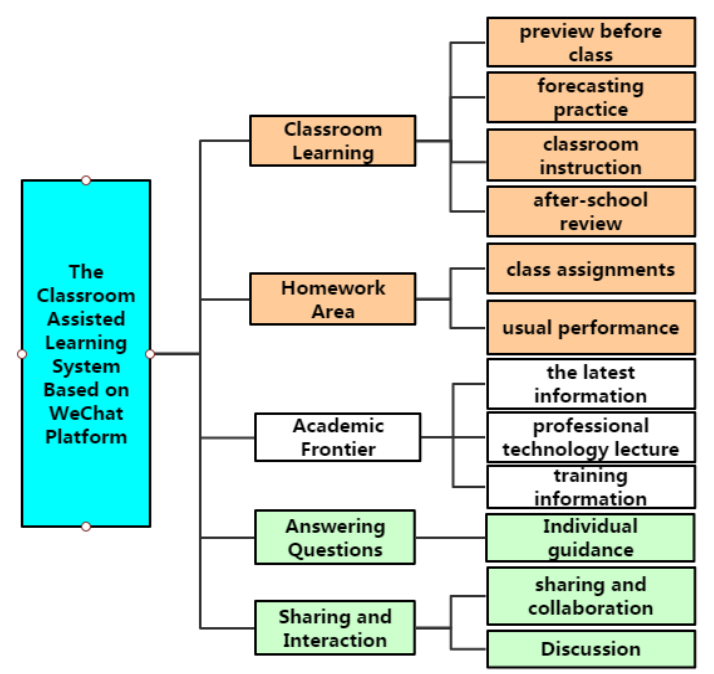

Fig. 2 the function structure chart of classroom assisted learning system based on WeChat platform

(1)Classroom Learning: It will help students to master the learning content of each lesson about the course and transferred to the interface of web's system by the way of hyperlink, curriculum in the form of a catalogue directly list, listing in order for the first class, the second class, the three classes et al. Each course is divided into four aspects of preview before class, forecasting practice, classroom instruction, after-school review to help students to grasp the real-time dynamic of each class and to provide students with learning guide in the classroom and curriculum. Then students can easily make study plans of the curriculum. This system is as a supplement to classroom learning, so the classroom synchronization is much stressed. At the beginning of opening the first class, every week to unlock the teaching content of the next class in advance, at the end of the semester we can see the whole course.

(2)Homework Area: It is divided into two modules of class assignments and usual performance. After the course is unclocked, the teacher can publish classrom homework, which could be queried by students at any time. After unlocking the next class, a standard answer of last class's homework will be released for students learning reference.

(3)Academic Frontier: In order to let the students make the knowledge closely attached to the social development, the system can publish irregularly the latest information and professional technology lecture information, which could help students to grasp the latest professional knowledge and closely contact with academic cattle to encourage themselves to learn.

(4)Answering Questions: This module provides students with personalized guidance and one-on-one conversation way to communicate. The students will encounter all kinds of problems in the course of studying and completing assignments, here you can submit your questions.

(5)Sharing and Interaction: Students and teachers in this platform both can upload information related the course to share their learning experience. Through the interactive communication in the process of discussion, students can learn from each other and learn from others' strong points and close the gap and accumulate experience.

\subsection{System Implementation}

According to the functional design, selecting C Program Design course to develop the classroom assisted learning system about $\mathrm{C}$ and release to the WeChat offical account. After students paying attention to the WeChat offical account, they input the username and password to login. After entering the system, you can query learning information of each course and the latest information of the course. And interactive question and answer function are provided for the system to promote the communication of students. After student logging and entering WeChat, the main interface of the classroom assisted learning system is shown as figure 3. The column of curriculum contains the two functional modules of "Classroom Learning“ and "Homework Area“; "Frontier" column contains the three function modules of the latest information, lectures and training practice; "teacher-student 
interaction" column contains Answering Questions and Sharing, which is convenient for students to ask questions and discuss.

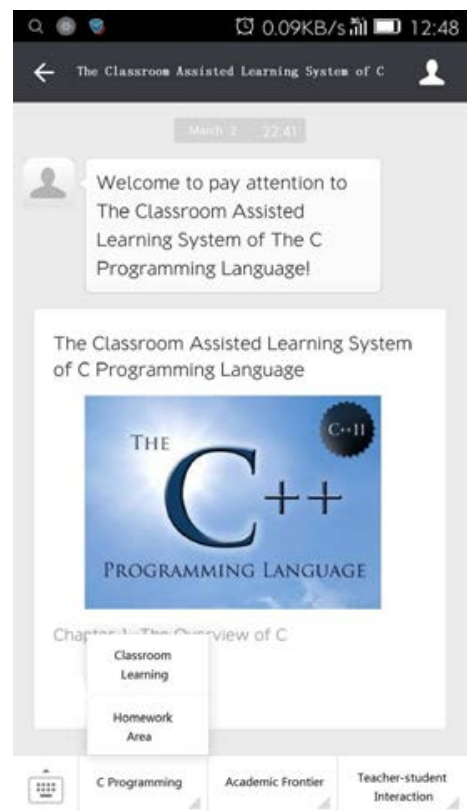

Fig. 3 The WeChat main interface of Classroom assisted learning

In the column of "C Program", after entering the "Classroom Learning" menu option, there will be a list of courses, gradually unlocking course with the teaching schedule. Only opening the content of the first class at the starting, the rest are locked and unable to enter. Clicking to enter the first class, there will appear four modules of the preview, prediction practice, classroom instruction, and after-class review. In the learning process of the actual course, the teacher will publish the teaching content which students should preview in advance into the preview module, and prepare appropriate predictive questions for the forecasting exercises module. In the classroom instruction module, there is the class teaching content and the corresponding micro video to save the time of copying the PPT courseware and taking notes according to the blackboard.

The column of "Academic Frontier" updates the latest information news about the course irregularly and provides students with the forefront information of social, lectures about the courses, training and internship's opportunities. In the column of "teacher-student interaction", teachers and students can freely share technological resources and discuss academic issues to promote each other. At the same time, students will have the opportunity to get the teacher's individual guidance by asking questions. In practice, students can self-study according to their own needs to click on different course content to achieve on-demand learning and change passive learning into active learning, which is a useful complement to classroom learning.

\subsection{The feedback}

For testing positive significance that the classroom assisted learning system products for learning and reflecting the effect of its usage, this paper selects two classes of "C Programming" course to conduct experiments. And at the end of the semester, a questionnaire survey was conducted on all the students who pay attention to the public WeChat offical account, and the part of the students was surveyed through face-to-face interviews, the feedback information is as follows:

(1)General Impression: All the students interviewed affirm the mobile learning support of WeChat. $95 \%$ of the students interviewed said, it is a mobile learning support tool aimed at specific curriculum after entering the university for the first time. $84 \%$ of the students said they would see the content in WeChat every day and is willing to accept the auxiliary teaching method.

(2)Function Evaluation: The sort of commonly used menu function, the first is the function of "Classroom Learning". The relevant contents of the books can also query, but the way of WeChat is more convenient, the communication between teachers and students is more intuitive, reflecting the 
superiority of mobile, which is followed by "Homework Area", "Answering Questions", "Sharing and Interaction" and "Academic Frontier" function.

In the feedback of the deficiencies of the course of WeChat platform, some think that the learning content of WeChat platform is relatively monotonous and lack of interest. Some students suggested adding the online test function which is similar to the game that one or more people to play in the WeChat platform, and there are also students recommended to integrate the query function of attendance, experimental results and test results into the WeChat platform.

\section{Conclusion}

With the development of the intelligent terminal and mobile Internet, students' learning mode gradually develops pure classroom learning into the combination of mobile learning software and platform to facilitate learning. Futher constant research and development of mobile learning software and platform also continuously promote the innovation and development of the learning model. Mobile learning is developing gradually as a new form of learning, and smart phone has become one of the important carriers of new learning form. The writer have proposed the new learning mode of using smart phone assisted classroom teaching in Colleges and universities, and have designed and developed the system of an auxiliary class teaching in Colleges and universities based on the WeChat platform. And the writer selected a specific course into practical use and good effects were achieved. But we also obtained valuable comments and the later time the system will be improved constantly based on students' feedback. With the continuous improvement of the performance of smart phones and costs continue to reduce, the application of smart phones in the classroom assisted learning is just around the corner, and the development of smart phones in the classroom assisted learning field will have broader prospects.

\section{References}

[1]. Vatrapu, R. K., Kocherla, K., \& Pantazos, K. (2013).IKlassroom: Real-Time, Real-Place Teaching Analytic, Leuven, Belgium, April 8, 2013.[Proceedings of the 2nd International Workshop on Teaching Analytics].

[2]. Ormond Simpson. Overcoming the 'Distance Education Deficit' through Proactive Motivational support. Distance Education in China, Beijing vol. 07, pp: 5-11, 2013.

[3]. W. Chuanxue, and Z. Hongjian. The design of micro class mobile teaching system based on intelligent mobile phone with Web platform. Distance Education in China, Beijing, and vol.12:60-66, 2014.

[4]. R. Shigui and Z. Yanlin. Classroom Data Visualization: Value and Teaching Application. Modern Distance Education Research, vol.1, pp: 104-112, 2016.

[5]. Q. Liu, Y. Fan. Practice and Discussion of Wechat Course in Open and Distance Education--A Case Study on "Wechat Class" in Wuxi Radio and TV University. Journal of Jiangsu Open University, 2015.

[6]. S. Mengzi. Tencent QQ and WeChat Effects on Interpersonal Relationship of College Students and Countermeasures. Science and Technology Communication, vol.7, pp: 101-109, 2015.

[7]. L. Hongxia, Z. Wei, Duo Shaojun. The Design and Practice of Classroom Collaborative Learning Support Mobile Technology. China Educational Technology, vol. 317, pp: 86-92, 2013.

[8]. Wang Ping. Analysis of Support Functions and Design Principles of Mobile Learning Based on Wechat. Distance Education in China, vol.6, pp: 34-41, 2013.

[9]. Yuan Lei, Chen Xiaohui, ZhangYanli. Study on Blended Learning in WeChat under the Support of "Basic Photography Technology" Course as an Example. China Educational Technology, vol.7, pp: 128-132, 2012.

[10]. Li Zhihe, Wang Lan, FengLixing. Research and Design of Database System for College Network Teaching in Higher Vocational College. Distance Education in China, pp: 69-75, 2013. 